\title{
A IMAGEM DO ENFERMEIRO NO INSTAGRAMNO CONTEXTO DA PANDEMIA DA COVID-19
}

Kalyane Kelly Duarte de Oliveira ${ }^{1}$ Vaniely Oliveira Ferreira ${ }^{1}$

Thaina Jacome Andrade de Lima ${ }^{1}$ Maria Valéria Chaves de Lima ${ }^{1}$ https://orcid.org/0000-0001-7713-3264 https://orcid.org/0000-0002-3423-6885 https://orcid.org/0000-0003-1289-8842 https://orcid.org/0000-0002-9278-5612

Objetivo: identificar a imagem do enfermeiro no contexto da pandemia da COVID-19 veiculada no Instagram. Método: pesquisa documental descritiva com abordagem quantitativa, desenvolvida usando hastags para buscar imagens e vídeos do Instagram que retratam a imagem da Enfermagem na pandemia da COVID-19. A análise dos dados foi por estatística descritiva. Resultados: $91 \%$ das publicações são fotos e apenas 9\% são em vídeo. A hastag Enfermagem trouxe um maior número de imagens, 49\%, enquanto a hastag COVID-19 trouxe apenas $8 \%$. Os órgãos governamentais são responsáveis por $4 \%$, as empresas por $9 \%$, organizações não governamentais por $15 \%$, e pessoas físicas por $72 \%$ das publicações. As 100 imagens selecionadas tiveram repercussões bem diferentes, baseando-se no número de likes na rede, variando de 139 a 1.300.000 likes. Ainda são fortemente veiculadas na mídia as impressões de heroísmo, abdicação e religiosidade. Conclusão: Afirma-se que a Enfermagem é uma categoria profissional essencial na linha de frente para a luta contra à COVID-19, mas ainda tem a sua imagem minimizada frente aos demais profissionais de saúde, além disso, a imagem é marcada por características dos primórdios da profissão. Conclui-se que para a enfermagem ser valorizada e alcançar suas lutas, precisa revestir-se cada vez mais da cientificidade em seus cuidados.

Descritores: Enfermagem; Redes sociais; Pandemias; Infecções por coronavirus.

\section{THE IMAGE OF NURSES ON INSTAGRAM IN THE CONTEXT OF THE PANDEMIC OF COVID-19}

Objective: to identify the nurse's image in the context of the COVID-19 pandemic broadcast on Instagram. Method: descriptive documentary research with a quantitative approach, developed using hastags to search images and videos from Instagram that portray the image of Nursing in the COVID-19 pandemic. Data analysis was performed using descriptive statistics. Results: $91 \%$ of publications are photos and only $9 \%$ are on video. The hastag Nursing brought a greater number of images, 49\%, while the hastag COVID-19 brought only $8 \%$. Government agencies are responsible for $4 \%$, companies for $9 \%$, non-governmental organizations for $15 \%$, and individuals for $72 \%$ of publications. The 100 images selected had very different repercussions, based on the number of likes on the network, ranging from 139 to $1,300,000$ likes. Impressions of heroism, abdication and religiosity are still strongly conveyed in the media. Conclusion: It is stated that Nursing is an essential professional category in the front line for the fight against COVID19, but its image is still minimized compared to other health professionals, in addition, the image is marked by characteristics of the early days of profession. It is concluded that for nursing to be valued and to reach its struggles, it needs to be more and more scientific in its care.

Descriptors: Nursing; Social networks; Pandemics; Coronavirus infections.

\section{LA IMAGEN DE ENFERMERAS EN INSTAGRAMAS EN EL CONTEXTO DE LA PANDEMIA DA COVID-19}

Objetivo: identificar la imagen de la enfermera en el contexto de la transmisión de la pandemia COVID-19 en Instagram. Método: investigación documental descriptiva con un enfoque cuantitativo, desarrollado utilizando hastags para buscar imágenes y videos de Instagram que retratan la imagen de Enfermería en la pandemia da COVID-19. El análisis de los datos se realizó mediante estadística descriptiva. Resultados: el $91 \%$ de las publicaciones son fotos y solo el $9 \%$ están en video. Hastag Nursing trajo una mayor cantidad de imágenes, $49 \%$, mientras que hastag COVID-19 trajo solo 8\%. Las agencias gubernamentales son responsables del $4 \%$, las empresas del $9 \%$, las organizaciones no gubernamentales del $15 \%$ y las personas del $72 \%$ de las publicaciones. Las 100 imágenes seleccionadas tuvieron repercusiones muy diferentes, en función del número de me gusta en la red, que van desde 139 hasta 1,300,000 me gusta. Impresiones de heroísmo, abdicación y religiosidad todavía se transmiten fuertemente en los medios de comunicación. Conclusión: Se afirma que la Enfermería es una categoría profesional esencial en la primera línea para la lucha contra COVID19, pero su imagen aún se minimiza en comparación con otros profesionales de la salud, además, la imagen está marcada por las características de los primeros días de profesión. Se concluye que para que la enfermería sea valorada y alcance sus luchas, debe ser cada vez más científica en su cuidado.

Descriptores: Enfermeria; Redes sociales; Pandemias; Infecciones por coronavirus.

${ }^{1}$ Curso de Enfermagem, Campus Avançado de Pau dos Ferros (CAPF), Universidade do Estado do Rio Grande do Norte (UERN). Autor Correspondente: Thaina Jacome Andrade de Lima. E-mail: thainajacome@hotmail.com Recebido: 04/5/2020 - Aceito: 28/5/2020 


\section{INTRODUÇÃO}

O vírus SARS-CoV-2 causador da COVID-19, nome dado a doença, é bastante parecido com as duas cepas causadoras da Síndrome Respiratória Grave Aguda (SARS), que já haviam sido estudadas anteriormente, todos de origem zoonótica. Assim, ao tornar o homem um hospedeiro do vírus, a transmissão passa-se a ser de pessoa para pessoa através de aerossóis ${ }^{(1)}$.

O percurso da doença seguiu-se inicialmente na cidade de Wuhan na China, havendo assim a propagação para outras províncias chinesas e para outros 27 paises e regiões. O primeiro caso confirmado fora da China foi na Tailândia, em 13 de janeiro e nos meses de fevereiro e março se espalhou em mais de 200 países e territórios com alta velocidade de contágio proporções que fez a Organização Mundial de Saúde (OMS) declarar o surto como pandemia em 11 de março de $2020^{(2)}$.

Devido a isto, os esforços para que os serviços ofertados sejam eficientes e qualificados para o combate à pandemia tem sido incessante. A nível global, a OMS tem feito apelos que têm resultado em investimentos em estudos e obtenção de dados, que ajudem a entender cada dia mais, o comportamento do vírus dentro e fora do ser humano. A corrida para a elaboração de medidas para conter a pandemia acontece simultaneamente em todos os setores: econômicos, transportes, educação e saúde. O que comprova que a crise do coronavirus é uma crise global, levando o mundo a um colapso(3).

Assim, as medidas emergenciais para socorrer a forma grave da doença tem sido foco de todos os países atingidos. A junção dos setores em prol do aumento na produção de materiais, assim como a criação de hospitais de campanha e ambulatórios, a contratação de profissionais e a elaboração de protocolos para reorganizar o serviço tem sido uma luta diária. A adoção de medidas profiláticas como o distanciamento social, a lavagem assidua das mãos, o não compartilhamento de objetos e o uso de álcool gel passaram a ser pontos fortes de debate e apelo a população(3).

A chegada do vírus ao Brasil instaurou, a exemplo mundial, um clima de instabilidade econômica e social. Em 16 de março, vários Estados anunciaram o isolamento social como a principal medida anunciada para contenção da pandemia, a exemplo de outros países, com o funcionamento apenas de serviços essenciais de alimentação e medicamentos, por exemplo. Logo, iniciou-se o embate entre o presidente e governadores de vários Estados, levantando discussões sobre a importância de economia e da preservação de vidas(4).
Nesse contexto destaca-se os profissionais de saúde que são quem, de maneira direta, tem o maior contato com os pacientes contaminados. Em destaque a Enfermagem, que realiza as principais atividades de cuidado e conforto aos acometidos.

A Enfermagem é uma ciência que tem como objeto de trabalho e estudo o cuidado ao ser humano, individualmente, na família ou em comunidade, de modo integral e equânime. O profissional enfermeiro desenvolve, de forma autônoma ou em equipe, atividades de promoção, proteção, reabilitação e recuperação da saúde, como também de prevenção de riscos e agravos ${ }^{(5)}$.

A escolha de 2020 como o Ano Internacional da Enfermagem não é mero acaso, é uma alusão ao bicentenário do nascimento de Florence Nightingale (18201910), precursora da Enfermagem Moderna. Outro fato que convida a destacar a Enfermagem é a campanha Nursing Now (Enfermagem Agora, em tradução livre). O Conselho Internacional de Enfermeiras (CIE), a Organização Mundial de Saúde (OMS) e o All Party Parliamentary Group on Global Health do Reino Unido, lançaram em fevereiro de 2018, a campanha como estratégia para o empoderamento dos profissionais de enfermagem e conta com a adesão de 30 países $^{(6)}$.

No Brasil, é realizada pelo Conselho Federal de Enfermagem (Cofen) em parceria com o Centro Colaborador da OMS para o Desenvolvimento da Pesquisa em Enfermagem, vinculado à Universidade de São Paulo/ Ribeirão Preto. O objetivo principal Nursing Now Brasil consiste em apresentar os profissionais de enfermagem como os verdadeiros protagonistas da saúde brasileira ${ }^{7}$

Nesse caminho discursivo emerge o questionamento: Qual a imagem da Enfermagem nas redes sociais no contexto da epidemia da COVID-19? A relevância dessa pesquisa consiste na importância de olhar as imagens construídas sobre a Enfermagem, uma vez que é força de trabalho predominante nos serviços de saúde no Brasil.

A imagem pode significar tanto o quadro que uma pessoa tem do objeto de sua vivência, quanto a opinião, contra ou a favor, que o público pode ter de uma instituição, organização ou personalidade ou ainda o conceito de que uma pessoa goza junto a outrem ${ }^{(5)}$.

Em relação à profissão, a imagem de qualquer categoria profissional, na sociedade, pode ser associada a poder, reconhecimento e status. Por isso, o que a sociedade pensa do profissional é tão importante quanto aquilo que ele é; pois a projeção de uma imagem negativa dificulta o desenvolvimento da profissão 
e seu reconhecimento por parte da sociedade. A Enfermagem tem utilizado pouco e mal os meios de comunicação para elucidar a comunidade científica e a população em geral sobre suas competências e seu papel na sociedade. Pesquisas no Brasil e no mundo retratam a "invisibilidade" do profissional em relação a seus clientes $^{(5)}$

Assim o estudo objetiva identificar a imagem do enfermeiro no contexto da pandemia da COVID-19 veiculada no Instagram.

\section{MÉTODO}

\section{Tipo de estudo}

Trata-se de uma pesquisa documental descritiva com abordagem quantitativa. O cenário da pesquisa foi o Instagram por ser um ambiente em que as pessoas integram fluxos de informação e reconhecem a existência de opções da informação que desejam acessar e compartilham segundo contexto em que se encontram.

\section{Cenário do estudo}

O Instagram foi criado por Kevin Systrom e Mike Krieger e lançado em outubro de 2010. O serviço rapidamente ganhou popularidade, com mais de 100 milhões de usuários ativos. Em 9 de abril de 2012, o Facebook adquiriu o Instagram por aproximadamente 1 bilhão de dólares. A rede social online permite o compartilhamento de fotos e vídeos entre seus usuários, permite aplicar filtros digitais e compartilhá-los em uma variedade de serviços de redes sociais, como Facebook, Twitter, Tumblr e Flickr. Os vídeos foram permitidos na rede em junho de 2013, com um limite de 15 segundos, pode-se também publicar gravações de até 60 segundos, desde janeiro de $2016^{(8)}$

O Instagram é bastante popular entre os brasileiros que têm acesso à internet. Desde 2015, a presença de brasileiros na plataforma é maior do que a média global. Em 2016, esse número subiu para $75 \%$, mais do que os $42 \%$ da média global do mesmo ano. Em 2019 os brasileiros estão em terceiro lugar no ranking de uso, ficando atrás apenas dos Estados Unidos e da Índia. Segundo especialistas, um dos motivos para a grande presença de brasileiros em mídias sociais e aplicativos como o Instagram é a combinação de um país bastante social com uma crescente penetração de smartphones no Brasil. Curiosamente, não se trata apenas de uma rede social utilizada pelos jovens - 57\% dos usuários brasileiros de internet na faixa dos 55 aos 65 anos também usam o Instagram ${ }^{(8)}$.

\section{População e amostra}

A amostra deste estudo foi composta pelas publicações do Instagram, seja imagens ou vídeos. Foram considerados como critério de inclusão na pesquisa hastags utilizadas conforme orienta a busca na rede social \#enfermagem, \#COVID-19, \#coronavírus, \#sars-cov-2. publicações em língua portuguesa, que no título do grupo apresentem intenção de serem para enfermeiro. Como critério de exclusão: páginas repetidas, páginas privadas, sem imagem no perfil, postagem de gifts, boomerang e em língua estrangeira.

\section{Coleta de dados}

Os dados foram coletados em formulário elaborado para o estudo. O formulário busca informações como: postagem em foto ou vídeo, ano de fundação da página, número de seguidores, ano e categoria da postagem, entre outros.

A coleta aconteceu no mês de abril de 2020, através de duas contas do Instagram, pessoais das pesquisadoras. Descartou-se as postagens repetitivas. O formulário era respondido logo após a visualização do vídeo ou imagem, sendo preenchidos os dados e as impressões das publicações.

Durante a pesquisa com a hashtag coronavirus encontrou-se 945.768 publicações, com a \#Sarscov2 46.464, \#Enfermagem 2.028.986, \#COVID19 11.073.309 e com \#pandemia 868.919, totalizando 14.963 .446 postagens e dessas foram selecionadas as 100 publicações. Justifica-se a quantidade escolhida, pois grande parte das publicações estavam voltadas ao marketing de empresas e pessoal, bem como postagem de fotos pessoais com a hashtag a fim de crescimento pessoal.

\section{Análise de dados}

Os dados foram analisados através de estatística descritiva simples, utilizando como suporte o Microsoft Excel 365 e discutidos a partir de referencial teórico pertinente.

\section{Aspectos éticos}

O estudo não requer aprovação do comitê de ética, uma vez que os dados utilizados são de domínio público, expostos no Instagram, porém, os autores atestam que todos os princípios éticos foram seguidos conforme a resolução 466/2012.

\section{RESULTADOS}

Entre os principais resultados encontrados es- 
tão 91\% das publicações são fotos e apenas 9\% são em vídeo. Os vídeos possuem uma duração variável de acordo com a forma de publicação, sendo no feed apenas de 60 segundos e no IGTV, que pode vir a ter até 10 minutos de vídeo. As postagens são todas de 2020, aumentando o número de postagens de acordo com o aumento do número de casos da doença, então evidencia-se um aumento do número de postagens entre os meses de março e abril do ano corrente.

Tabela 1: Hastags utilizadas para busca

\begin{tabular}{|l|c|c|}
\hline \multicolumn{1}{|c|}{ Hashtag } & № & $\%$ \\
\hline \#Coronavirus & 15 & 15 \\
\hline \#COVID19 & 8 & 8 \\
\hline \#Enfermagem & 49 & 49 \\
\hline \#Pandemia & 13 & 13 \\
\hline \#Sarscov2 & 15 & 15 \\
\hline Total & 100 & 100,0 \\
\hline
\end{tabular}

Outro resultado encontrado é a origem das publicações: os órgãos governamentais são responsáveis por 4\%, as empresas por 9\%, Organizações não governamentais por $15 \%$, e pessoas físicas por $72 \%$ das publicações. As 100 imagens selecionadas tiveram repercussões bem diferentes, baseando-se no número de likes na rede, variando de 139 a 1.300 .000 likes.

Tabela 2: categorias das publicações

\begin{tabular}{|l|c|c|}
\hline \multicolumn{1}{|c|}{ Categoria } & № & $\%$ \\
\hline Ciência e tecnologia & 9 & 9,0 \\
\hline Educação & 11 & 11,0 \\
\hline Entretenimento & 1 & 1,0 \\
\hline Notícias e política & 5 & 5,0 \\
\hline Pessoas e blogs & 74 & 74,0 \\
\hline TOTAL & 100 & 100,0 \\
\hline
\end{tabular}

Algumas impressões quanto ao perfil da enfermagem ficaram evidentes durante a coleta de dados sendo elas captadas a partir da percepção subjetiva acerca das publicações. No gráfico 1, no tópico "outros tipos de informação", está relacionado a postagens de manchetes, propagandas e dados informativos de como acontece a propagação da COVID-19.

Gráfico 1: Impressões sobre a enfermagem captadas das imagens

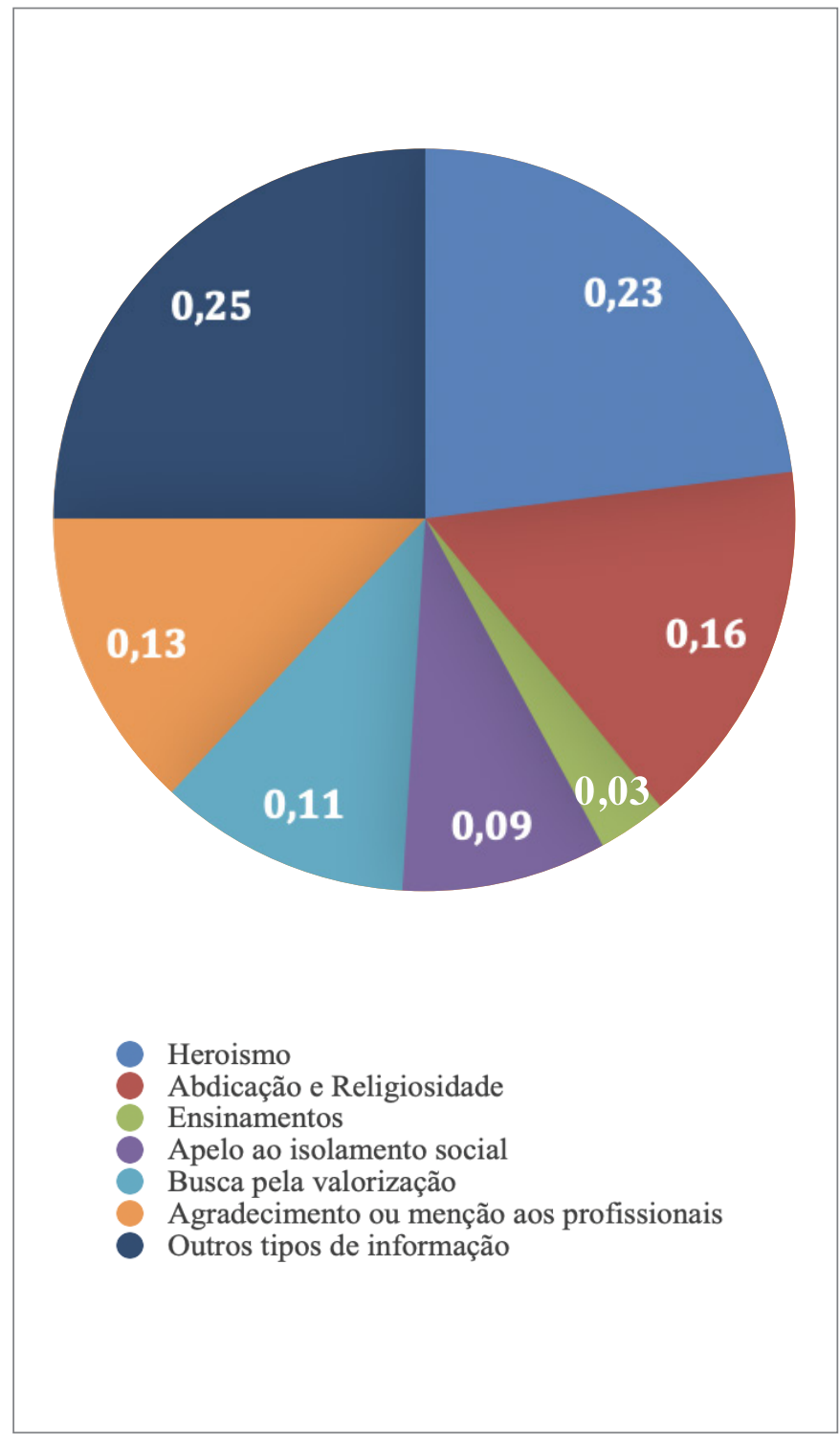

\section{DISCUSSÃO}

As mídias selecionadas tinham relação com a Enfermagem e com seu profissionalismo. A análise minuciosa evidenciou algumas características predominantes que merecem maior atenção e ponderamentos quanto a seus impactos. A primeira delas é que o reconhecimen- 
to do profissional do enfermeiro parte na maioria das vezes de perfis pessoais, com pouco número de seguidores que querem expor seu agradecimento e valorização à Enfermagem por um meio de veiculação global. O fato das postagens acontecerem nesta modalidade de perfil justifica o pouco alcance de visualizações e a pequena visibilidade do enfermeiro nesta rede social.

Essa perspectiva reflete em estudos apontando que pessoas com mais seguidores costumam ser as melhores formas de obter reconhecimento de algo, ou gerar divulgação ou até mesmo vender uma ideia. Pessoas ou páginas com este tipo de perfil são formadores de opinião e propagadores de um estilo de vida, sendo esses chamados de Influenciadores Digitais. Diferente de quem tem poucos seguidores ou um perfil pessoal, essas pessoas costumam ter apoio financeiro e midiático, de modo que o que eles expõem em suas páginas ganha uma centralidade global, que pode favorecer ou distorcer a imagem de algo ou alguém em poucos minutos com um simples post ${ }^{(9)}$. Constata-se que não é isso que parece ocorrer com os profissionais da Enfermagem que mantém os perfis.

Outro ponto que se destacou através da análise dos dados foi que a ação dos profissionais de enfermagem na linha de frente de combate à COVID-19 acentuou o caráter religioso que a profissão já tem. Tanto nas legendas quanto nas imagens, o enfermeiro aparece com o perfil angelical, e de abdicação, sendo que desta vez, a renúncia de sua rotina e família em prol da saúde é real, ainda que não seja pela perspectiva religiosa, mas sim por questões estatais, necessárias e acima de tudo emergenciais.

Autores reforçam que a Enfermagem vive uma montanha russa quanto às suas formas de visão aos olhos da sociedade. Os estudiosos apresentam a luta constante da Enfermagem historicamente em se desprender dos estigmas que a profissão carregava desde seu surgimento. Revezando entre o demérito de religiosa, caridosa, depois sensual, sem ciência e predominantemente feminina, até chegar ao que é hoje, uma profissão que faz e é ciência, ainda que por deslizes vez ou outra vista-se de uma de suas roupagens antigas, seja pelos próprios profissionais ou pela nação em si(10)

O enfermeiro também aparece em alguns momentos como um herói, o que nem sempre é uma titulação que favorece para a valorização da profissão. Tendo em vista que a ideia de herói transmite a percepção de um alguém forte que trabalha sem descanso, que muito gosta do anonimato, e que não precisa de mostrar seu rosto para agir, a identificação heroica da Enfermagem acaba por levar a contradição lutas que esses profissionais traçaram a anos quanto ao piso salarial e as tão sonhadas trinta horas.

Em algumas imagens a equipe de Enfermagem também aparece segurando um planeta ou prestando cuidados ao mesmo o que faz nos refletir sobre a ideia de que esse profissional tantas vezes acaba realmente carregando um peso muito grande de dezenas de pessoas. Como por exemplo, inúmeros hospitais em que apenas um enfermeiro assume a responsabilidade de cuidar de mais pacientes do que o que se é preconizado.

Quanto a essas percepções, propõem se críticas que se aplicam a algumas destas ideias. Ao fazer uma retrospectiva riquissima sobre a identidade profissional do enfermeiro na mídia brasileira, os autores apontam este trabalhador como um ser humano comum. Pois, embora trabalhe na saúde e esteja apto cientificamente a cuidar e prestar serviços ao próximo, é um ser que também está sujeito a falhas, e que merece compreensão e valorização quanto a seus serviços e lutas ${ }^{(11)}$

O enfermeiro também aparece em alguns momentos trocando de lugar com o paciente que perpassa de curado a alta, enquanto o profissional assume a posição de recém adoecido. O que nos faz refletir quanto ao perfil de adoecimento desse profissional no serviço, e acima de tudo o perfil de adoecimento desta categoria agora em meio a pandemia que já é alarmante e desfalca fortemente o quadro de profissionais necessários para o combate à COVID-19.

Analisando essa preocupação, o Conselho Federal de Enfermagem criou um formulário online e um observatório próprio para realizar um balanceamento quanto ao número de profissionais que estão infectados no país. Os levantamentos feitos pelo Conselho mostram que há mais de 4 mil profissionais da Enfermagem contaminados pela COVID-19 e mais de cem mortos em todos país. E como uma forma de proteger os seus, assim como de cuidar dos próximos que precisam dos serviços da enfermagem,

O Conselho Federal de Enfermagem (Cofen) tem postado vídeos, cursos e informações para capacitar ainda mais a categoria. E como forma de prevenção a quem está na linha de frente e também para homenagear os que se encontram doentes e os que faleceram em meio a luta, a organização mobiliza a ideia de que "Proteger a Enfermagem é proteger a saúde do Brasil", seguido dos dizeres "Cuidamos da Enfermagem para que ela cuide de todos"(12). 
Por fim uma das percepções mais preocupantes quanto a análise foi a de que apenas $11 \%$ das mídias retrata de alguma forma a busca pela valorização da Enfermagem. Felizmente essa busca é uma luta que vem sendo levantada por órgãos muito relevantes como a Organização Mundial de Saúde, que instaurou a campanha do Nursing Now em parceria com o Conselho Internacional de Enfermagem e iniciou-se em 2018.

O recente chamado à liderança dos enfermeiros pela Campanha Nursing Now e o enfrentamento da COVID-19, explicitou que valorizar é mais um dos desafios diante das condições de trabalho vigentes, consideradas insatisfatórias; os recursos humanos e materiais disponíveis são insuficientes para atender a população que bate às portas dos serviços e não encontra resolutividade, criando problemas de proporções legais e éticas. No ambiente em movimento, entre valorização e desafios, a enfermagem desdobra-se para manter-se atualizada, propor inovações, mantendo uma postura ética diante da responsabilidade que lhes é dada por ofício $^{(13)}$.

Enfatiza-se que entre todos os profissionais que compõe as equipes de saúde, a enfermagem destaca-se por trazer consigo a arte do cuidar, referindo-se ao enfermeiro como líder, esse destaca-se gerindo equipes, resolvendo conflitos, tomando decisões que norteiam a a assistência. A figura do enfermeiro deve nortear a equipe na busca por melhorias e satisfação profissio$\mathrm{nal}^{(14)}$.

Evidencia-se ainda que muitas limitações vivenciadas pela equipe de enfermagem na prática contribuem para a falta de valorização profissional, mas essas limitações decorrem dos desafios enfrentados no cotidiano do trabalho e que se reflete em sua pratica profissional: dificuldades na consolidação de uma equipe interdisciplinar; deficiência quantitativa de profissionais da categoria, gerando sobrecarga; falta de recursos materiais e a cultura popular centrada no modelo biomédico. Essas situações implicam diretamente em lacunas na eficácia dos serviços prestados pela equipe de enfermagem ${ }^{(15)}$.

Por fim, afirma-se a importância de que a gestão dos serviços minimize problemas no processo de trabalho e estimule a capacitação dos profissionais de enfermagem para que a valorização desses profissionais seja uma constante nos serviços de saúde ${ }^{(15)}$.

\section{Limitações do estudo}

Aponta-se como limitações a disponibilidade de arti- gos científicos sobre a temática e a mudança constante de informações, visto que à COVID-19 é uma doença nova, exigindo mais investigações. Cita-se ainda, as dificuldades para encontrar um número considerável de materiais que se enquadrassem no objetivo da pesquisa.

\section{Contribuições para a prática}

O estudo contribui para explicitar que a Enfermagem ocupa um espaço singular e decisivo no contexto da pandemia por COVID-19, mas ainda assim tem a sua imagem minimizada ou subestimada, mesmo com uma campanha de valorização vigente, a Enfermagem ainda precisa justificar sua existência enquanto área profissional dentro da sociedade. Contribui ainda, na sensibilização para repensar estratégias de valorização da Enfermagem seja no ensino, pesquisa, serviço, gestão e em todos os campos de atuação.

\section{CONCLUSÃO}

Diante do exposto afirma-se que a Enfermagem é uma categoria profissional essencial na linha de frente para a luta contra à COVID19, conquanto ainda tenha a sua imagem minimizada quando comparado aos demais profissionais que também se encontram nessa luta. Evidenciou-se também que a imagem guarda as heranças dos primórdios da profissão, como religiosidade, abdicação, vocação. Essas ainda persistem em aparecer como perfil da enfermagem do século XXI, o que deixa claro que para a enfermagem ser valorizada e alcançar suas lutas, precisa revestir-se cada vez mais da cientificidade em seus cuidados.

Provocar mudanças na imagem da profissão veiculada nas redes sociais exige a retratação profissional de forma verossimil, frisando o objeto de conhecimento e trabalho da profissão e, ainda punindo a comunicação de inverdades divulgadas.

\section{CONTRIBUIÇÕES DOS AUTORES}

a) concepção e/ou desenho do estudo; Kalyane Kelly Duarte de Oliveira e Vaniely Oliveira Ferreira;b) coleta, análise e interpretação dos dados; Thaina Jacome Andrade de Lima e Maria Valéria Chaves de Lima; c) redação e/ou revisão crítica do manuscrito; Kalyane Kelly Duarte de Oliveira, Vaniely Oliveira Ferreira, Thaina Jacome Andrade de Lima e Maria Valéria Chaves de Lima;d) aprovação da versão final a ser publicada: Kalyane Kelly Duarte de Oliveira, Vaniely Oliveira Ferreira, Thaina Jacome Andrade de Lima e Maria Valéria Chaves de Lima 


\section{REFERÊNCIAS}

1. Zi YZ, Meng DJ, Peng PX, Wen C, Qian QN, Guang ML. et al. Coronavirus disease 2019 (COVID-19): A perspective from China. RSNA Journals, 2020 Fev. O (0) p. 200490. Disponível em <https://pubs.rsna. org/doi/full/10.1148/radiol.2020200490> Acesso em 03 de abril de 2020.

2. Ensheng D, Hongru D, Lauren G. Um painel interativo baseado na Web para rastrear à COVID-19 em tempo real. As doenças infecciosas Lancet, 2020 Fev. 20 (5) 533-534. Disponivel em: <https://www. thelancet.com/journals/laninf/article/PIIS14733099(20)30120-1/fulltext> Acesso em 03 de abril de 2020

3. Fundação Osvaldo Cruz. Plano de contingência da Fiocruz diante da pandemia da doença pelo SARS-CoV-2 (COVID-19): Fiocruz, 2020 abr. 1.4. 1-20 Disponivel em: <https://www.arca.fiocruz. br/handle/icict/40335> Acesso em 03 de abril de 2020 .

4. Macedo YM,Ornellas JL, Bomfim HF. COVID-19 NO BRASIL: O que se espera para população subalternizada?. Rev. Encantar-Educação, Cultura e Sociedade. Jan/dez 2020. 2, p. 01-10. Disponível em <http://www.revistas.uneb.br/index.php/encantar/ article/view/8189>Acesso em 04 de abril de 2020

5. Souza RV, Alves LC, Barra LLLB, Fernandes LM, Salgado PO, Viegas SMF. Imagem Do Enfermeiro Sob A Ótica Do Acadêmico De Enfermagem. Enferm. Foco. 2017; 8 (1): 47-51. Disponivel em: <http://revista.cofen.gov.br/index.php/enfermagem/article/view/763/363>. Acesso em: 01 maio 2020. doi:https://doi.org/10.21675/2357-707X.2017. v8.n1.763.

6. Crisp N, Iro E. Nursing now campaign: raising the status of nurses. Lancet. 2018 [cited 2020 Apr 13];391(10124):920-1. Available from: https:// www.thelancet.com/journals/lancet/article/PIIS0140-6736(18)30494-X/fulltext

7. Cassiani SHB, Lira Neto JCG. Nursing Perspectives and the "Nursing Now" Campaign. Rev Bras Enferm. 2018[cited 2020 Apr 15];71(5):2351-2. Available from: http://www.scielo.br/pdf/reben/ v7ln5/0034-7167-reben-71-05-2351.pdf
8. https://exame.abril.com.br/tecnologia/estes-sao-os-dez-paises-que-mais-usam-o-instagram/ Acesso em 11 de abr. de 2020

9. Silva CRM, Tessarolo FM. Influenciadores digitais e as redes sociais enquanto plataformas de midia. XXXIX Intercom 2016. Disponivel em <http://portalintercom.org.br/anais/nacional2016/resumos/ R11-2104-1.pdf> Acesso em 24 de abril de 2020

10. Cunha YFF, Sousa RR. Gênero e enfermagem: um ensaio sobre a inserção do homem no exercício da enfermagem. RAHIS, 2016 ago. 13 (3). 140149. Disponivel em <https://revistas.face.ufmg.br/ index.php/rahis/article/view/140-149> Acesso em 24 de abril de 2020 .

11. Silva AR, Padilha MI, Backes VMS, Carvalho JB. Identidade profissional de enfermagem: uma perspectiva através das lentes da midia impressa brasileira. Esc. Anna Nery, 2018 jan; 22 (4)1 -8. Disponivel em <http://www.scielo.br/scielo.php?pi$\mathrm{d}=$ S1414-81452018000400223Escript=sci_arttextEtlng=pt> Acesso em 24 de abril de 2020.

12. Conselho Federal de Enfermagem (COFEN). Disponivel em: http://juntoscontracoronavirus.com. br/. Acesso em 28 de abril de 2020.

13. Angerami ELS. Nursing: dialogue with the past in the commitment to the present. Rev Latino-Am Enfermagem. 2019 [cited 2020 Apr 14]; 27: e 3220. Available from: http://www.scielo.br/pdf/rlae/ v27/0104-1169-rlae-27-e3220.pdf

14. Mattos JCO, Balsanelli AP. A liderança do enfermeiro na atenção primária à saúde: revisão integrativa. Enferm Foco. 2019. 10 (4). 164-171 Disponivel em: http://revista.cofen.gov.br/index.php/ enfermagem/article/view/2618 Acesso em 21 de maio de 2020

15. Moll MF, Boff NN, Silva PS, Siqueira TV, Ventura CAA. O enfermeiro na saúde da família e a promoção de saúde e prevenção de doenças. Enferm Foco. 2019. 10 (3).134-140. Disponivel em: http://revista.cofen.gov.br/index.php/enfermagem/article/view/2001Acesso em 21 de maio de 2020 